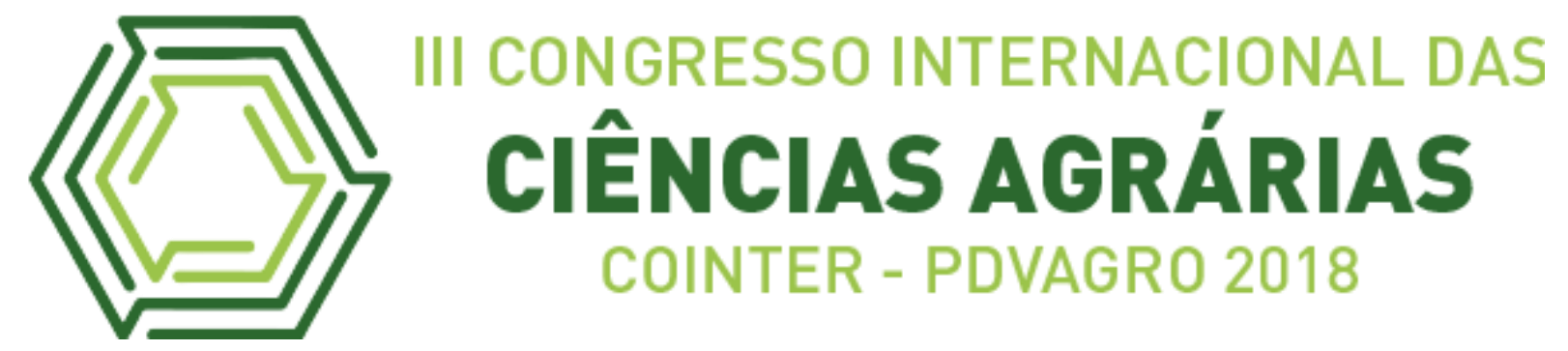

\title{
MANEJO GERAL DA SUINOCULTURA DO CAMPUS IFPE VITÓRI DE SANTO ANTÃO
}

\section{GENERAL MANAGEMENT OF THE PIG OF THE CAMPUS IFPE VITÓRI DE SANTO ANTÃO}

\author{
Apresentação: Relato de Experiência \\ Max Jefferson da Silva Nascimento ${ }^{1}$; Amanda Karolaine Lima da Silva ${ }^{2}$; Marta Xavier \\ de Carvalho Correia ${ }^{3}$
}

DOI: https://doi.org/10.31692/2526-7701.IIICOINTERPDVAGRO.2018.00745

\section{Introdução}

O estágio significa aprendizagem, ou seja, estudos práticos para a experiência em determinado assunto ou profissão e aprimoramento do desenvolvimento profissional. (MEDEIROS et al 2006). Segundo o Instituto Evaldo Lodi (2010), o estágio é um ato educativo escolar supervisionado, desenvolvido no ambiente de trabalho que visa à preparação para o trabalho produtivo do estudante. Neste contexto, o estágio curricular é compreendido como um processo de experiência prática, que aproxima o acadêmico da realidade de sua área de formação e o ajuda a compreender diversas teorias que conduzem ao exercício da sua profissão.

O estágio é uma excelente alternativa para a inserção de jovens no mercado de trabalho, proporcionando o desenvolvimento das competências profissionais, dando a possibilidade de enfrentar desafios e aprimorando a capacidade de julgamento, decisão e intervenção diante do novo e do inusitado (CNE/CEB 35/2003).

É a oportunidade que o acadêmico tem para realizar a inter-relação entre a teoria assimilada ao longo do curso com a prática propriamente dita, além de ter a prerrogativa de conhecer o funcionamento das instituições que desenvolvem atividades com ênfase no seu campo de atuação, moldando assim um profissional com condições ímpares para atuarem com qualidade em seu local de trabalho.

Apresentaremos neste trabalho uma vivencia de estágio do curso subsequente de

\footnotetext{
${ }^{1}$ Zootecnia, IFPE - Instituto federal de Pernambuco, maxjefferson388@gmail.com

${ }^{2}$ Zootecnia, IFPE - Instituto federal de Pernambuco, amandalimaazul@gmail.com

${ }^{3}$ Doutora, IFPE - INSTITUTO FEDERAL DE PERNAMBUCO, $\underline{\text { marta.xavier@vitoria.ifpe.edu.br }}$
} 
zootecnia. Objetivamos assim, buscar relacionar a teoria aprendida em sala de aula com as práticas realizadas durante a vivência do estágio.

\section{Relato de Experiência}

A realização do estágio ocorreu no Setor de Suinocultura do Campus IFPE Vitória de Santo Antão, município de Pernambuco durante um período de 3 meses. As atividades que foram desenvolvidas foram relativas ao manejo alimentar, reprodutivo e ao manejo de recémnascidos além da limpeza e desinfecção das instalações.

Durante o estágio, teve-se a oportunidade de realizar atividades práticas acercar do manejo com os suínos. No manejo alimentar dos animais, as rações eram compostas basicamente por farelo de milho, de soja, e de trigo, suplementados com minerais e vitaminas, fornecidas duas vezes ao dia e a água fornecida através de bebedouros "chupetas" que ficam na altura do dorso do animal.

Realizou-se atividades de higienização das instalações (imagem 1) evitando a contaminação por bactérias e agentes patológicos que comprometem a saúde do animal. No manejo reprodutivo, as fêmeas gestantes precisaram de cuidados específicos durante o manejo para que não se estressassem evitando assim, as perdas embrionárias. Foi feito também o manejo de leitões recém-nascidos até o fornecimento do desmame. A realização dessas atividades permitiu uma integração da teoria aprendida em sala de aula com a prática realizada referente aos manejos dos animas e instalações, possibilitando assim, um entendimento mais eficaz acercar da teoria aprendida e contribuiu de forma gradativa para adquirir experiências de como se devem manejar esses animais.

No manejo dos animais recém-nascidos, um ponto principal é fazer com que os leitões mamem o colostro (imagem 2), levando os filhotes até as tetas da mãe. O colostro é nada mais nada menos que o primeiro leite produzido após o parto e apresenta propriedades nutricionais, imunológicas e laxativas importante para o desenvolvimento e saúde das crias. Foi feito o fornecimento de calor suplementar para os leitões, através de campanulas elétricas, com a finalidade de aquecê-los, contornando os problemas no seu aparelho termorregulador. Realizou-se também o corte dos dentes e de caudas como medida preventiva contra o canibalismo. Fez-se a marcação pelo método australiano, é importante fazer isto para a identificação do animal e quanto mais jovem ele for melhor pois o registro dos seus dados zootécnicos se inicia logo no primeiro dia com o peso de nascimento. 
Após a realização dessas atividades, foi perceptível que boas práticas de manejo interferem na qualidade de vida e produção dos animais, porque uma alimentação de qualidade, o ambiente limpo, o manejo adequado possibilitam o controle de doenças e isto contribui para o bem-estar do animal. Alguns fatores como a criação, alimentação, manejo e abate contribuem para uma boa ou má qualidade da carne suína. Sabe-se que a qualidade da carne é intimamente influenciada pelas particularidades de produção, que englobam fatores como manejo, sanidade, efeitos genéticos, ambientais e alimentares dos animais (MILLER 2002). Todas as práticas de manejo desenvolvidas durante o período de estágio, contribuíram para manter cuidado com os recém-nascidos até o abate visando assim, uma melhor qualidade de vida dos suínos e de sua carne por tentar reduzir ao máximo que o animal passasse por algum tipo de estresse, doenças, desequilíbrios nutricionais e entre outros fatores que contribuíssem com estes fatos.

Essa experiência foi imensamente satisfatória e enriquecedora por possibilitar aplicação prática de conteúdos abordados em sala de aula, influenciando de uma forma significativa o desenvolvimento das atividades referente as práticas de manejo. Através dessa experiencia, foi possível adquirir conhecimentos práticos necessários para a formação profissional e pessoal do técnico em zootecnia.

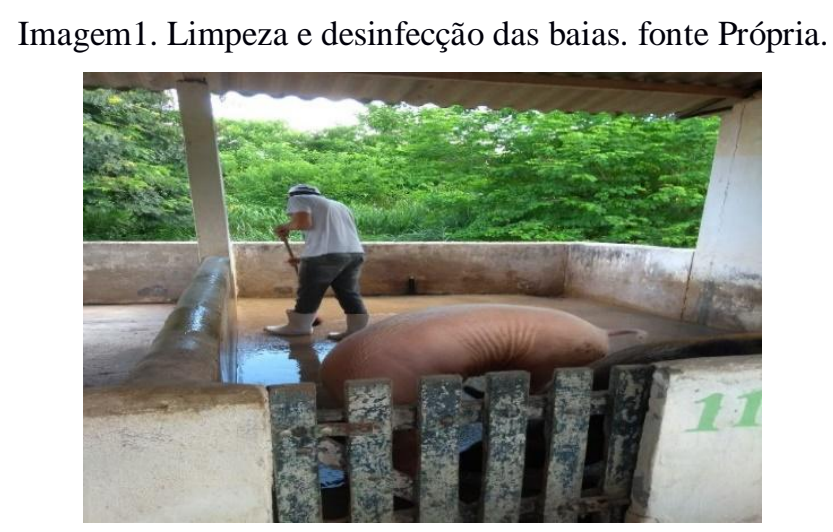


Imagem 2. Fornecimento do colostro. Fonte: Própria.

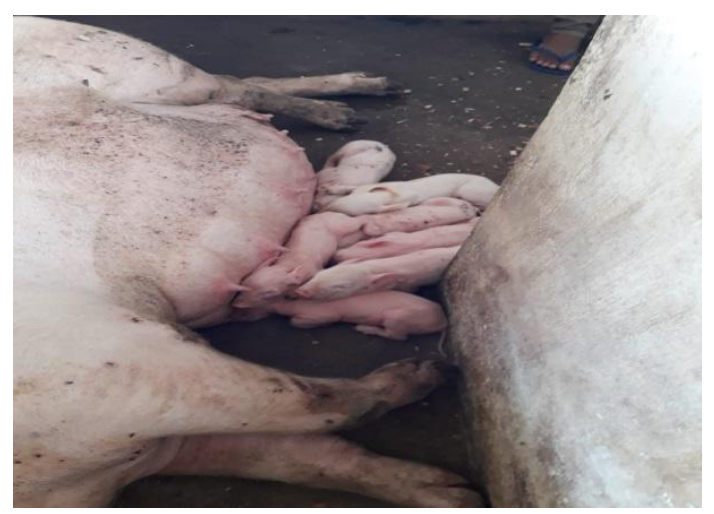

\section{Considerações}

O estágio curricular supervisionado é de fundamental importância para o desenvolvimento do estudante tanto no eixo profissional quanto no eixo acadêmico, proporcionando uma oportunidade ao estudante de adquirir experiência na sua área de atuação. É durante o estágio que o aluno irá por em prática seus conhecimentos como também adquirir novos, adequando e transferindo soluções práticas diante dos problemas encontrados diariamente em um sistema de produção animal. Além disso, é através deste período que o profissional irá tentar se encaixar no mercado de trabalho uma vez que contribuirá para aumentar o número de contatos com os profissionais da área.

Boas práticas de manejo animal, associadas com as normas higiênicas sanitárias são fundamentais para se obter sucesso na criação e longevidade para a produção.

\section{Referências}

CNE/CEB 35/2003. Normas para a organização e realização de estágio de alunos do Ensino Médio e da Educação Profissional. Conselho Nacional de Educação/Câmara de Educação Básica. 2003.

INSTITUTO EVALDO LODI. Lei de Estágio: Tudo o que você precisa saber. Brasília, 2010. p. 73.

MEDEIROS, D. et al. Manual de estágio: Geografia, História e Letras. Rio de Janeiro, 2006.

MILLER, R. K. Factors effecting the qualities of raw meat. In: KERRY, Joseph, KERRY, John; LEDWARD, David (Eds.). Meat processing: improving quality. Cambridge: Woodhead Publishing Limited e CRC Press LLC, 2002. Cap. 3, p. 24-63. 